\title{
10. Acclimation to a New Hall
}

I am often asked if I am nervous on opening night. While certainly exciting, we are already quite familiar with the acoustics of the hall by the time we reach opening night. For us, the most nervous moment is the first rehearsal. The hall is new to everyone: to the conductor and musicians, managers, and to us as acousticians.

The first rehearsal for Walt Disney Concert Hall was on June 30, 2003, coincidentally the 45th birthday of conductor Esa-Pekka Salonen. After a few hours of rehearsal, I had some discussion with the concertmaster, principal clarinet, and other section leaders. They were concerned with the conditions in the new hall and reported that the stage acoustics were problematic and that they found it difficult to hear themselves and each other. If this had been our first hall, I would have panicked at this point. However, this is a very normal occurrence. At the first rehearsal, the musicians may be nervous, causing them to play louder, and forcing everyone else to play louder to hear their own sound. This further deteriorates the ability for others to hear their own sound, potentially devolving into chaos. Instead, I recommended that everyone played softer and focused on listening.

Two weeks later at the second rehearsal, I met again with the section leaders who now reported that they were much more able to hear each other. They wondered what had I changed. Of course nothing had changed, there was only more time to acclimate to hearing each other in the new hall. While it is possible for conditions to change if the tail end of construction overlaps with rehearsals, the changes would be small. More likely is that the musicians are becoming more and more comfortable in the space.

I think of this process in the same way as moving in to a new house. It takes a few days to discover which way the doors open and which lights correspond to which switches. This does not mean that there is some inherent flaw in the house, only a lack of familiarity. In a concert hall, the "family" moving in can be well over a hundred people, so the effect is magnified. For this reason, we suggest that the first notes in the hall are from a soloist or small ensemble before working up to a full orchestra. The situation will improve most dramatically in the early days and weeks, but is still noticeable after two to three years depending on the relationship between the orchestra and the hall.

Even for those we now consider the best halls, there would have been some moving-in period. Vienna Musikvereinssaal and Berlin Philharmonie both have world-class orchestras, but the stage acoustics in the Musikvereinssaal are very different from the Philharmonie. Even these top-notch musicians prefer their home hall over the other, but there is no way to say which pairing of orchestra and concert hall are best. Familiarity developed through time is one of the most essential components of stage acoustics. The importance of hours of rehearsals in a concert venue cannot be overstated.

Over the course of years, many-especially musicians - may feel that the hall acoustics have changed. I believe this longterm effect is mostly tied to unreliable memory. The acclimation of the musicians to the new hall gives the effect that the hall has somehow "matured" since their last tour. For example, Daniel Barenboim reported to me that he was surprised by the improvement in the acoustics in Suntory Hall since his first visit with Orchestre de Paris soon after the opening. I have no doubt that his impression was different, but there is no indication that the room itself had physically changed.

To this end, I have no personal evidence nor have I read any research which would imply that some physical change is causing the hall to change its acoustical characteristics. Musicians report that their instruments change, and that the wood and varnish become increasingly resonant with use over the years, making it logical to assume that a hall would similarly mature as well. In some ways, a building does act like a big instrument where some components such as the stage wood may physically mature. However, the plaster surfaces and concrete structure which make up most of the reflecting surfaces in a hall have no mechanism or benefit to age.

Fortunately, the changes reported are almost always positive. 